\title{
Human Spectrin. III. A Study Based on Dynamic and Static Light Scattering
}

\author{
ARILD BØE, ${ }^{a}$ ARNLJOT ELGSAETER, ${ }^{b}, *$ GUNNHILD OFTEDAL ${ }^{b}$ and KNUT A. STRAND ${ }^{a}$
}

\author{
${ }^{a}$ Institute of Experimental Physics and ${ }^{b}$ Institute of Biophysics, The Norwegian Institute of \\ Technology, N-7034 Trondheim-NTH, Norway
}

The translational diffusion coefficient, $D_{20}^{\circ}$, of human spectrin extrapolated to zero spectrin concentration and referring to $20^{\circ} \mathrm{C}$ was determined employing the dynamic light scattering technique. Measurements on spectrin heterodimers at the ionic strength $(I)$ of $0.001 \mathrm{M}(\mathrm{pH} 7.3)$ and $0.1 \mathrm{M}$ $(\mathrm{pH} 7.5)$ gave $D_{20}^{\circ}=(1.03 \pm 0.08) \times 10^{-11} \mathrm{~m}^{2} / \mathrm{s}$ and $D_{20}^{\circ}=(1.40 \pm 0.05) \times 10^{-11} \mathrm{~m}^{2} / \mathrm{s}, \quad$ respectively. Measurements on spectrin heterotetramers at $I=0.1$ $\mathrm{M}(\mathrm{pH} 7.5)$ yielded $D_{20}^{\circ}=(0.95 \pm 0.08) \times 10^{-11} \mathrm{~m}^{2} / \mathrm{s}$. The static light scattering measurements on spectrin heterotetramers at $I=0.1 \mathrm{M}\left(\mathrm{pH} \mathrm{7.5)}\right.$ and $22{ }^{\circ} \mathrm{C}$ gave a radius of gyration of $(60 \pm 10 \mathrm{~nm})$. Light scattering measurements on solutions $(I=0.1 \mathrm{M}$, $\mathrm{pH}$ 7.5) containing spectrin heterodimers at room temperature further indicated that (a) spectrin monomerization occurred as the temperature was raised slowly to $47-48{ }^{\circ} \mathrm{C}$, (b) there was a sharp transition at $49{ }^{\circ} \mathrm{C}$ as revealed by the formation of high molecular weight spectrin aggregates.

Spectrin is a major protein component of the human erythrocyte membrane ${ }^{1,2}$ located on its cytoplasmic surface. $^{3}$ The spectrin heterodimers contain two large polypeptide chains with molecular weights of approximately 230000 and 250000 Dalton. Spectrin heterotetramers probably consist of two spectrin heterodimers. ${ }^{4}$

Spectrin is thought to play a major role in determining many of the biophysical properties of the erythrocyte membrane such as shape, ${ }^{5}$ viscoelasticity ${ }^{6}$ and lateral mobility of the intramembrane particles. $^{7-9}$ Spectrin removal from isolated erythrocyte membranes causes ghosts to lose their characteristic biconcave shape and become spherical

\footnotetext{
* To whom reprint requests should be addressed.
}

and fragile, eventually versiculating into smaller membrane fragments. ${ }^{7}$ The details of how spectrin plays its important roles are not known. Any new information about the spectrin structure is therefore of great interest.

The published structural data on spectrin are rather bewildering. The reported spectrin lengths vary from $28 \mathrm{~nm}$ to $210 \mathrm{~nm} .^{10-11}$ We have earlier reported on a classical light scattering study and an electro-optic study indicating that spectrin heterodimers are expanded flexible worm-like or coil-like molecules with a radius of gyration that increases from about $22 \mathrm{~nm}$ to about $40 \mathrm{~nm}$ as the ionic strength is reduced from $0.1 \mathrm{M}$ to $0.001 \mathrm{M} .^{12,13}$ Here we report on dynamic light scattering measurements of spectrin heterodimers and heterotetramers, as well as static light scattering measurements of spectrin heterotetramers.

In dynamic light scattering experiments the objective of the basic measurements is characterization of the timescale of the scattered light intensity fluctuations. This can be done by determining the normalized intensity correlation function:

$$
g_{\mathrm{r}}(\vec{q}, \tau) \equiv\langle I(\vec{q}, t) I(\vec{q}, t+\tau)\rangle\left\langle\langle(\vec{q}, t)\rangle^{2}\right.
$$

where $I(\vec{q}, t)$ is the intensity of the scattered light, $\vec{q}$ is the scattering vector, $t$ is the time and \langle\rangle denotes time average. When the complex representation of the electric field of the scattered light, $E(\vec{q}, t)$, has a Gaussian distribution, the Siegert relation connects $g_{1}(\vec{q}, t)$ and the first-order field correlation function: ${ }^{14}$

$g_{1}(\vec{q}, \tau)=1+\left|g_{\mathrm{E}}^{(1)}(\vec{q}, \tau)\right|^{2}$ 
where:

$g_{\mathrm{E}}^{(1)}(\vec{q}, \tau) \equiv \frac{\left\langle E(\vec{q}, t) E^{*}(\vec{q}, t+\tau)\right\rangle}{\left\langle E(\vec{q}, t) E^{*}(\vec{q}, t)\right\rangle}$

It can be shown ${ }^{15}$ that for a monodisperse solution of independent macromolecules the following relationship is valid provided that the dimensions of the macromolecules are small compared to $q^{-1}$ :

$\left|g_{\mathrm{E}}^{(1)}(\vec{q}, \tau)\right|=\exp (-\Gamma|\tau|)$

Here $\Gamma=D q^{2}, q=|\vec{q}|$, and $D$ is the translational diffusion coefficient of the macromolecules. When the dimensions of the macromolecules are of the same order of magnitude as or larger than $q^{-1}$, internal and rotational movements of the macromolecules may cause significant changes in the correlation properties of the scattered light. ${ }^{15}$ The decay constant will then not be proportional to $q^{2}$. More detailed introductions to dynamic light scattering have been given by various authors. ${ }^{16-19}$

For spheres $D$ is given by the Stokes-Einstein relation: ${ }^{20}$

$D=k T /(6 \pi \eta R)$

where $k$ is the Boltzmann constant, $T$ the absolute temperature, $\eta$ the viscosity of the solvent and $R$ the radius of the sphere. For non-spherical molecules one can introduce an equivalent hydrodynamic radius:

$R_{\mathrm{e}} \equiv k T /(6 \pi \eta D)$

It is further customary to introduce the parameters ${ }^{20} f / f_{\min }=R_{\mathrm{e}} / R_{\mathrm{o}}$ and $\xi \equiv R_{\mathrm{e}} / R_{\mathrm{G}}$, where $R_{\mathrm{o}}$ is the macromolecule radius of the same molecule in the hypothetical form of an unsolvated compact sphere, and $R_{\mathrm{G}}$ is the macromolecule radius of gyration. For compact spheres the frictional ratio $f / f_{\min }=1$ and $\xi=\sqrt{5 / 3} .^{20}$ The frictional ratio increases with increasing axial ratio for stiff prolate ellipsoids and an axial ratio of 50 gives $f / f_{\min } \simeq 3$. For random coils $\xi=0.665^{21}$ and for stiff rod-like molecules of constant length $\xi \rightarrow 0$ when the rod diameter is reduced to zero.

The light scattering data presented here support the conclusions drawn in our earlier studies, ${ }^{12,13}$ which indicated that the spectrin heterodimer is a flexible and highly expanded worm-like or coil-like molecule.

\section{EXPERIMENTAL}

Except for one modification the spectrin heterodimers were prepared according to procedures referred to as $A$ and $B$ in an earlier study. ${ }^{12}$ The last step in procedure $\mathrm{A}$ is gel filtration at $0-4{ }^{\circ} \mathrm{C}$ on a Sepharose CL-4B column $(2.6 \mathrm{~cm} \times 90 \mathrm{~cm})$ equilibrated with $0.1 \mathrm{M} \mathrm{NaCl}, 0.5 \mathrm{mM}$ EDTA and $0.05 \mathrm{mM}$ dithiothreitol $\mathrm{pH}$ 7.3. In the study reported here the last gelfiltration step was done at $22^{\circ} \mathrm{C}$ and having the Sepharose CL-4B column equilibrated with $0.1 \mathrm{M} \mathrm{NaCl}, 5 \mathrm{mM}$ EDTA, $5 \mathrm{mM} \beta$-mercaptoethanol and $10 \mathrm{mM}$ sodium phosphate $\mathrm{pH}$ 7.5. This modified procedure for preparation of spectrin heterodimers will in the following be referred to as procedure $A^{\prime}$.

Spectrin heterotetramers were prepared by first dialyzing the isolated human erythrocyte ghosts for $40-42$ hours at $0-4{ }^{\circ} \mathrm{C}$ against $2 \times 1000 \mathrm{ml} 0.1 \mathrm{mM}$ EDTA and $0.05 \mathrm{mM}$ dithiothreitol $\mathrm{pH}$ 7.5. The ghost suspension was then centrifuged at $200000 \mathrm{~g}$ (50 $000 \mathrm{rev} . / \mathrm{min}$ in a Beckman 50Ti rotor) for $60 \mathrm{~min}$ at $0-4{ }^{\circ} \mathrm{C}$ and the supernatant chromatographed on the gelfiltration column used in the last step in procedure $A^{\prime}$. The resulting elution profile was found to be very similar to that described earlier. ${ }^{12}$

The spectrin heterodimer and the spectrin heterotetramer solutions were optically clarified as described earlier. ${ }^{12}$

The static light scattering measurements were made at $436 \mathrm{~nm}$ employing a Brice-Phoenix Light Scattering Photometer (Model 2000) and a cylindrical sample cell (type C101) with flat entrance and exit window. ${ }^{2}$

The dynamic light scattering measurements were made at $\lambda=514.5 \mathrm{~nm}$ and 6-7 different angles, $\theta$, in the range $30-130^{\circ}$. As light source, an argon ion laser (Spectra Physics, maximum output $1.4 \mathrm{~W}$ at $514.5 \mathrm{~nm}$ ) was used. To improve the polarization of the incident laser beam a Glan polarizing prism (Halle, extinction ratio better than $10^{-5}$ ) was placed between the laser and the sample cell. The same sample cell was used for the static and the dynamic light scattering measurements. To obtain refractive index-matching and temperature control the sample cell was placed in a temperature-controlled water bath. The scattered light was detected using an ITT-FW 130 photomultiplier. The signals from the photomultiplier were analyzed employing a digital correlator (Malvern, 24 channels). The calculation of the translational diffusion coefficient is described in detail elsewhere. ${ }^{22}$

The setup for dynamic light scattering measurements was checked for systematic errors due to fluctuations in the light intensity from the laser, vibrations and selfcorrelation in the photomultiplier by measuring the intensity correlation function of fluorescence from a fluorescence standard (Applied 
Photophysics) which emits light around $560 \mathrm{~nm}$ when excited at $514.5 \mathrm{~nm}$. The normalized intensity correlation function of the fluorescence was found to deviate less than $0.4 \%$ from 1 in the time range of interest indicating that selfcorrelations in the spectrometer were negligible. The performance of the dynamic light scattering setup was further checked by measuring the translational diffusion coefficient of bovine serum albumin (BSA, Sigma, fraction $\mathrm{V}$ ). The translational diffusion coefficient of BSA in $150 \mathrm{mM} \mathrm{KCl}, 8 \mathrm{mM}$ phosphate buffer (pH 7.6) at $20{ }^{\circ} \mathrm{C}$ was found to be $(5.9 \pm 0.1) \times$ $10^{-11} \mathrm{~m}^{2} / \mathrm{s}$ which is in close agreement with the results reported by others. ${ }^{23}$ The amount of local heating in the spectrin solutions because of absorption of the laser beam was estimated employing the thermal lens effect described by Gordon et al. ${ }^{24}$ The local temperature rise was found to be less than about $0.2{ }^{\circ} \mathrm{C}$.

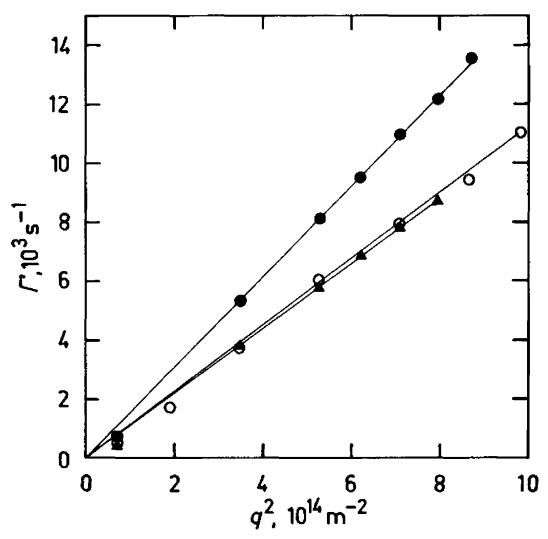

Fig. 1. The decay constant, $\Gamma$, of the first order field correlation function, referring to $20{ }^{\circ} \mathrm{C}$, as function of $q^{2}$ for (a) $72 \mu \mathrm{g} / \mathrm{ml}$ human spectrin heterodimers $(O)$ in $1 \mathrm{mM}$ Tris. $\mathrm{HCl}, 0.1 \mathrm{mM}$

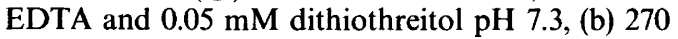
$\mu \mathrm{g} / \mathrm{ml}$ human spectrin heterodimers (๑) and (c) $240 \mu \mathrm{g} / \mathrm{ml}$ human spectrin heterotetramers $(\boldsymbol{\Delta})$ in $100 \mathrm{mM} \mathrm{NaCl}, 5 \mathrm{mM}$ EDTA, $5 \mathrm{mM} \beta$-mercaptoethanol and $10 \mathrm{mM}$ phosphate buffer $\mathrm{pH} 7.5$.

\section{RESULTS AND DISCUSSION}

In Fig. 1 is shown the decay constant $\Gamma$ as function of $q^{2}$. Since $\Gamma$ approximately is proportional to $q^{2}$, it is concluded that there is no significant contribution to the dynamic light scattering from the different spectrin solutions due to rotation or internal movement of the spectrin molecules. In the following $\Gamma / q^{2}$ is therefore interpreted as being equal to the translational diffusion coefficient of spectrin. Fig. 2 shows the measured translational diffusion coefficients, $D_{20}$, of spectrin heterodimers and spectrin heterotetramers at different spectrin concentrations referred to $20{ }^{\circ} \mathrm{C}$ by making the usual temperature/viscosity correction. The Zimm diagram $^{12,25}$ of spectrin heterotetramers at an ionic strength (I) of $0.1 \mathrm{M}$ is shown in Fig. 3. Our light scattering data of spectrin obtained at room tem-

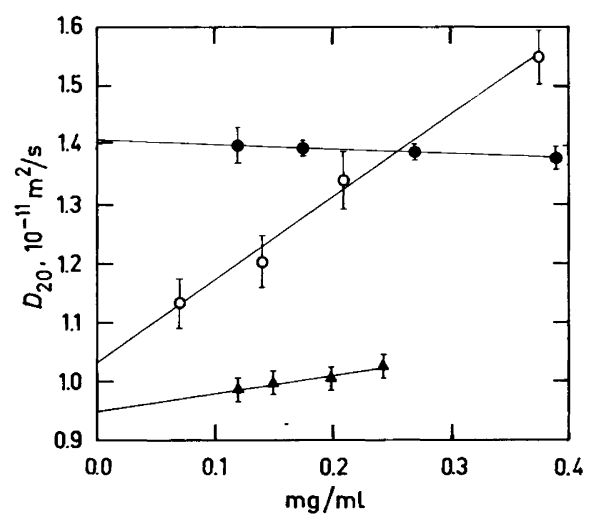

Fig. 2. The translational diffusion coefficient referring to $20{ }^{\circ} \mathrm{C}, D_{20}$, of (a) human spectrin heterodimers $(O)$ in $1 \mathrm{mM}$ Tris. $\mathrm{HCl}, 0.1 \mathrm{mM}$ EDTA and $0.05 \mathrm{mM}$ dithiothreitol $\mathrm{pH} 7.3$, (b) human spectrin heterodimers $(\bullet)$ and (c) human spectrin heterotetramers $(\Delta)$ in $100 \mathrm{mM} \mathrm{NaCl}, 5 \mathrm{mM}$ EDTA, $5 \mathrm{mM} \beta$-mercaptoethanol and $10 \mathrm{mM}$ phosphate buffer $\mathrm{pH} 7.5$.

Table 1. A summary of the human spectrin light scattering data. The symbols are explained in the text.

\begin{tabular}{llllllll}
\hline $\begin{array}{l}\text { Human } \\
\text { spectrin }\end{array}$ & $\begin{array}{l}\text { Ionic } \\
\text { strength } \mathrm{M}\end{array}$ & $\begin{array}{l}D_{20}^{\circ} \\
10^{-11} \mathrm{~m}^{2} / \mathrm{s}\end{array}$ & $\begin{array}{l}R_{\mathrm{o}} \\
\mathrm{nm}\end{array}$ & $\begin{array}{l}R_{\mathrm{e}} \\
\mathrm{nm}\end{array}$ & $\begin{array}{l}f / f_{\min }= \\
R_{\mathrm{e}} / R_{\mathrm{o}}\end{array}$ & $\begin{array}{l}\boldsymbol{R}_{\mathrm{G}} \\
\mathrm{nm}\end{array}$ & $\xi=R_{\mathrm{e}} / R_{\mathrm{G}}$ \\
\hline Heterodimers & 0.1 & $1.40 \pm 0.05$ & $5.2 \pm 0.2$ & $15 \pm 1$ & $2.9 \pm 0.2$ & $22 \pm 2^{a}$ & $0.7 \pm 0.1$ \\
Heterodimers & 0.001 & $1.03 \pm 0.08$ & $5.2 \pm 0.2$ & $20 \pm 2$ & $3.8 \pm 0.4$ & $45 \pm 5^{a}$ & $0.45 \pm 0.05$ \\
Heterotetramers & 0.1 & $0.95 \pm 0.08$ & $6.6 \pm 0.2$ & $23 \pm 2$ & $3.5 \pm 0.3$ & $60 \pm 10$ & $0.4 \pm 0.1$ \\
\hline
\end{tabular}

${ }^{a}$ From Ref. 12.

Acta Chem. Scand. A 33 (1979) No. 3 


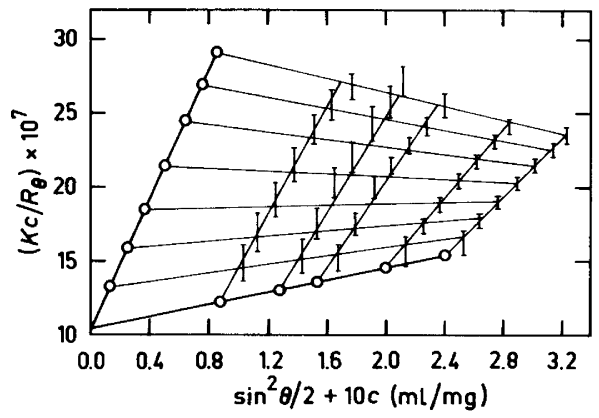

Fig. 3. Zimm plot for human spectrin heterotetramers in $100 \mathrm{mM} \mathrm{NaCl}, 5 \mathrm{mM}$ EDTA, $5 \mathrm{mM}$ $\beta$-mercaptoethanol and $10 \mathrm{mM}$ phosphate buffer (pH 7.5) at $22{ }^{\circ} \mathrm{C}$.

perature are summarized in Table $1 . R_{0}$ was calculated employing a spectrin heterodimer and heterotetramer molecular weight of 480000 and 960000 Dalton, respectively, and a spectrin partial specific volume of $0.73 \mathrm{ml} / \mathrm{g}$. ${ }^{10}$

The translational diffusion coefficient of flexible worm-like or coil-like molecules cannot be estimated without knowledge of contour length and the degree of molecular flexibility. However, both the obtained frictional ratios and the values $\xi$ are fully compatible with our earlier conclusion that spectrin is a highly expanded coil-like or worm-like molecule. ${ }^{12,13}$ Our light scattering data are certainly not compatible with spectrin being a compact globular protein. In $1 \mathrm{mM}$ Tris. $\mathrm{HCl}, \mathrm{pH} 7.3$ (Fig. 2) spectrin heterodimer $D_{20}$ was found to exhibit a strong concentration dependence. This is consistent with our earlier classical light scattering study which also indicated a strong heterodimer-heterodimer interaction in this solution. The $D_{20}^{\circ}$-values ( $D_{20}$ extrapolated to zero spectrin concentration) reported here for spectrin heterodimers and heterotetramers $(I=0.1 \mathrm{M})$ are about $10 \%$ lower than those values reported by Kam et al. ${ }^{10}$ This small discrepancy may well be ascribed to the use of different spectrin isolation and preparation procedures. For spectrin heterodimers in $1 \mathrm{mM}$ Tris. $\mathrm{HCl}$ (pH 7.3) $D_{20}^{\circ}$ has previously not been reported.

Our classical light scattering measurements of spectrin heterotetramers $(I=0.1 \mathrm{M})$ indicate that the spectrin heterotetramers prepared by us have a length of about $210 \mathrm{~nm}$ if the heterotetramers are stiff rod-like molecules. If the spectrin heterotetramers are worm-like or coil-like molecules, the end- to-end distance is less than $210 \mathrm{~nm}$, but the contour length is more than $210 \mathrm{~nm}$.

Kam et al. ${ }^{10}$ found that $R_{\mathrm{G}} \lesssim 8 \mathrm{~nm}$ for spectrin heterodimers and for heterotetramers they state: "As with the dimer there is little angular dependence of light scattering". For heterodimers they ${ }^{10}$ reported a decrease of less than $10 \%$ of the intensity of the scattered light as the scattering angle was increased from $30^{\circ}$ to $150^{\circ}$. The results of Kam et $a .^{10}$ therefore imply that also for the heterotetramer $\boldsymbol{R}_{\mathbf{G}} \lesssim 8 \mathrm{~nm}$. The relation of our observations to those of Kam et al. ${ }^{10}$ remains unclear. However, a recent electron microscopic study of spectrin by Shotton et al. ${ }^{26}$ fully supports our findings. In addition, it is worth noting that the results of $\mathrm{Kam}$ et al. ${ }^{10}$ give $\xi \gtrsim 1.7$ for spectrin heterodimers and $\xi \gtrsim 2.3$ for spectrin heterotetramers. Since $\xi \simeq 1.3$ for compact spheres and $\xi<1$ for prolate ellipsoids of revolution with axial ratio larger than about 3, the results of Kam et al. ${ }^{10}$ therefore appear to be internally inconsistent.

In Fig. 4 is shown $D_{20}$ and the relative intensity of the light scattered at $90^{\circ},\left(I_{90} / I_{0}\right)_{t}=20{ }^{\circ} \mathrm{C}$, of spectrin solutions $(I=0.1 \mathrm{M}, \mathrm{pH} 7.5)$ as the temperature was raised from room temperature to about $55^{\circ} \mathrm{C}$. From about 35 to $47-48{ }^{\circ} \mathrm{C}$ both $D_{20}$ and $\left(I_{90} / I_{0}\right)_{\mathrm{t}}$ exhibited some time-dependence. $D_{20}$ in-

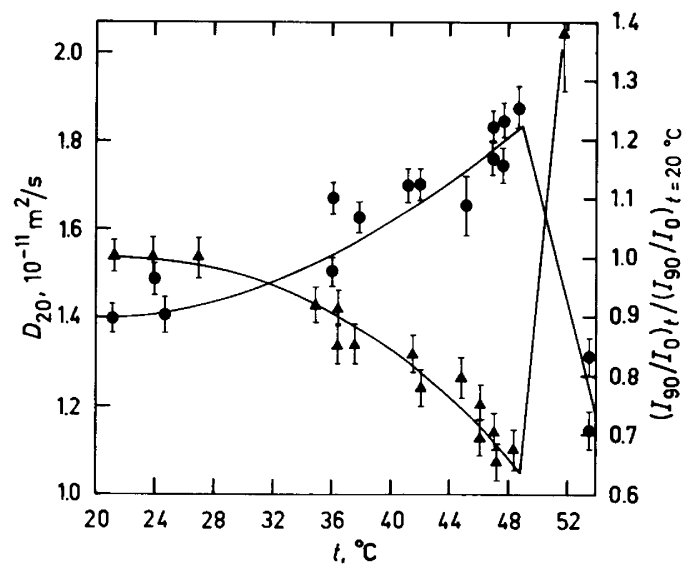

Fig. 4. The translational diffusion coefficient referring to $20{ }^{\circ} \mathrm{C}, D_{20}$, of solutions containing spectrin heterodimers $(120 \mu \mathrm{g} / \mathrm{ml})$ in $100 \mathrm{mM} \mathrm{NaCl}, 5 \mathrm{mM}$ EDTA, $5 \mathrm{mM} \beta$-mercaptoethanol and $10 \mathrm{mM}$ phosphate buffer $(\mathrm{pH} 7.5)$ at room temperature as function of temperature $(\bullet)$, and the relative intensity of the light scattered at $90^{\circ},\left(I_{90} / I_{0}\right)_{1} /$ $\left(I_{90} / I_{0}\right)_{t=20^{\circ} \mathrm{C}}$, normalized to 1 at $20^{\circ} \mathrm{C}$ as function of temperature $(\boldsymbol{\Delta})$. 
creased and $\left(I_{90} / I_{0}\right)_{4}$ decreased slowly with time at constant temperature. Above $49{ }^{\circ} \mathrm{C}\left(I_{90} / I_{0}\right)_{t}$ increased and $D_{20}$ decreased rapidly with time at constant temperature. The decrease in $\left(I_{90} / I_{0}\right)_{t}$ as the temperature was increased to $47-48{ }^{\circ} \mathrm{C}$ was not accompanied by an increase in the asymmetry of the light scattering envelope. The data shown in Fig. 4 therefore indicate that the spectrin heterodimers dissociate into monomers as the temperature is elevated and that spectrin to a large extent is monomerized at $47-48{ }^{\circ} \mathrm{C}$. Further increase of the temperature results in the formation of high molecular weight aggregates. Brants et al. ${ }^{27}$ have previously concluded from calorimetric and circular dichroism measurements that spectrin exhibits a sharp structural transition at $49^{\circ} \mathrm{C}$.

Our light scattering data indicate a monomerization of spectrin heterodimers $(I=0.1 \mathrm{M})$ when the temperature is raised to $47-48{ }^{\circ} \mathrm{C}$. The data reported here are further fully consistent with spectrin being expanded worm-like or coil-like molecules and that spectrin can make up a molecular network on the cytoplasmic side of the erythrocyte membrane as discussed prevuously. ${ }^{7,8}$

Acknowledgements. The authors thank Professor Torbjørn Sikkeland for his interest and support. The technical assistance of Ms. M. Engen is gratefully acknowledged. This work has in part been supported by a grant from "Norges Tekniske Høgskoles Fond" to A.E.

\section{REFERENCES}

1. Marchesi, V. T. and Steers, E. Science 159 (1968) 203.

2. Fairbanks, G., Stech, T. L. and Wallach, D. F. H. Biochemistry 10 (1971) 2606.

3. Nicolson, G. L., Marchesi, V. T. and Singer, S. J. J. Cell Biol. 51 (1971) 265.

4. Ralston, G., Dunbar, J. and White, M. Biochim. Biophys̀. Acta 491 (1977) 345.

5. Birchmeier, W. and Singer, S. J. J. Cell Biol. 73 (1977) 647.

6. Evans, E. A. Biophys. J. 13 (1973) 941.

7. Elgsaeter, A. and Branton, D. J. Cell Biol. 63 (1974) 1018.

8. Elgsaeter, A., Shotton, D. M. and Branton, D. Biochim. Biophys. Acta 426 (1976) 101.

9. Fowler, V. and Branton, D. Nature 268 (1977) 23.

10. Kam, Z., Josephs, R., Eisenberg, H. and Gratzer, W. B. Biochemistry 16 (1977) 5568.
11. Clarke, M. and Griffith, J. Fed. Proc. 31 (1972) 412.

12. Elgsaeter, A. Biochim. Biophys. Acta 536 (1978) 235.

13. Mikkelsen, A. and Elgsaeter, A. Biochim. Biophys. Acta 536 (1978) 245.

14. Glauber, R. J. In DeWitt, C., Blandin, A. and Cohen-Tannoudji, C., Eds., Quantum Optics and Electronics, Gordon Breach, New York 1965.

15. Cummins, H. Z., Carlson, F. D., Herbert, T. J. and Woods, G. Biophys. J. 9 (1969) 518.

16. Berne, B. J. and Pecora, R. Dynamic Light Scattering, Wiley, New York 1976.

17. Cummins, H. Z. and Pike, E. R. Photon Correlation and Light Beating Spectroscopy, Plenum, London-New York 1974.

18. Cummins, H. Z. and Pike, E. R. Photon Correlation Spectroscopy and Velocimetry, Plenum, London-New York 1977.

19. Chu, B. Laser Light Scattering, Academic, London-New York 1974.

20. Tanford, C. Physical Chemistry of Macromolecules, Wiley, New York 1961.

21. Kirkwood, J. G. and Rosemann, J. J. Chem. Phys. 16 (1948) 565.

22. Dalberg, P. S., Bøe, A., Strand, K. A. and Sikkeland, T. J. Chem. Phys. 69 (1978) 5473.

23. Raj, R. and Flygare, W. H. Biochemistry 13 1974) 3336.

24. Gordon, J. P., Leite, R. C. C., Moore, R. S., Porto, S. P. S. and Whinnery, J. R. J. Appl. Phys. 36 (1965) 3.

25. Zimm, B. H. J. Chem. Phys. 16 (1948) 1093.

26. Shotton, D., Burke, B. and Branton, D. Biochim. Biophys. Acta 536 (1978) 313.

27. Brandts, J. F., Erichson, L., Lysks, K., Schwartz, A. T. and Taverna, R. D. Biochemistry 16 (1977) 3450 .

Received September 4, 1978.

Acta Chem. Scand. A 33 (1979) No. 3 